\title{
PELATIHAN KOMUNIKASI INTERPERSONAL UNTUK MENINGKATKAN KOHESIVITAS KELOMPOK PADA KARYAWAN HOTEL X YOGYAKARTA
}

\section{INTERPERSONAL COMMUNICATION TRAINING TO ENCHANGE GROUP COHESIVENESS OF EMPLOYEE X YOGYAKARTA}

\author{
Didik Widiantoro \\ Sukarti \\ Sus Budiharto \\ Magister Psikologi Profesi, Fakultas Psikologi dan Ilmu Sosial Budaya \\ Universitas Islam Indonesia \\ Email : didikwidiantoro@psy.uir.ac.id
}

\begin{abstract}
This research is aiming for influence of interpersonal communication training to improve the cohesiveness of the group of employees. Subjects in this study were 22 employees of Hotel X of Yogyakarta, which is divided into 11 experimental groups of employees and 11 employees of the control group. Data collection is use cohesiveness scale, interviews, and observations. The research design was pretest-posttest control group design. Analysis of the study is a quantitative and qualitative analysis. Quantitative analysis using UMann Whitney to determine the effect of interpersonal communication training to the employee group cohesiveness. Qualitative analysis is based on observations and interviews. The results showed that there were significant differences in group cohesiveness in employees between the experimental group and the control group with significant value of $0.002(p<0.005)$. It is concluded that interpersonal communication training can enhance group cohesiveness in employees Hotel $X$ Yogyakarta.
\end{abstract}

Keywords: Interpersonal Communication Training, Cohesiveness group, Employee

\begin{abstract}
ABSTRAK
Penelitian ini bertujuan untuk mengetahui pengaruh pelatihan komunikasi interpersonal untuk meningkatkan kohesivitas kelompok pada karyawan. Subjek dalam penelitian ini adalah 22 orang karyawan Hotel X Yogyakarta yang dibagi dalam 11 karyawan kelompok eksperimen dan 11 karyawan kelompok kontrol. Pengumpulan data dilakukan dengan menggunakan skala kohesivitas, wawancara, dan observasi. Desain penelitian yang digunakan adalah pretest-posttest control group design. Analisis penelitian yang digunakan adalah analisis kuantitatif dan kualitatif. Analisis kuantitatif dengan menggunakan U-Mann Whitney untuk mengetahui pengaruh pemberian pelatihan komunikasi interpersonal terhadap kohesivitas kelompok pada karyawan. Analisis kualitatif dilakukan berdasarkan observasi dan wawancara. Hasil penelitian menunjukkan bahwa terdapat perbedaan kohesivitas kelompok yang signifikan pada karyawan antara kelompok eksperimen dan kelompok kontrol dengan nilai signifikan $0.002(p<0.005)$. Kesimpulan penelitian ini adalah pelatihan komunikasi interpesonal dapat meningkatkan kohesivitas kelompok pada karyawan Hotel X Yogyakarta.
\end{abstract}

Kata Kunci : Pelatihan komunikasi interpesonal, Kohesivitas kelompok, Karyawan 
Hotel X merupakan salah satu perusahaan yang menyediakan jasa penginapan yang berlokasi di Yogyakarta. Saat ini bisnis perhotelan dan penginapan di kota Yogyakarta berkembang sangat cepat. Diperoleh data dari dinas Pekerjaan Umum kota Yogyakarta terdapat lebih dari 150 hotel/wisma yang sudah terbangun ataupun dalam proses pengerjaan sepanjang tahun 2015. Hal ini tentu saja menimbulkan persaingan yang sangat ketat. Hotel X Yogyakarta terletak di pusat kota, dekat dengan lingkungan universitas dan juga pusat perkantoran. Akibatnya, lingkungan sekitar Hotel $X$ sangat padat dengan segala aktivitas.

Sesuai dengan tagline yang dimiliki oleh Hotel X yaitu "Sleep Well, Work Well", hotel X memberikan kenyamanan kepada seluruh pengguna jasa Hotel X, dengan memberikan pelayanan yang berkualitas sampai dengan tempat yang nyaman dan mewah. Hotel $X$ ini membawa konsep business hotel, dari mulai lokasi yang strategi sampai fasilitas yang lengkap dalam memberikan kenyamanan bagi pelanggan. Misalnya menyediakan akses internet yang merata baik di dalam kamar maupun di public area sehingga memudahkan bila tamu harus mengerjakan tugas atau laporan yang membutuhkan waktu cepat. Hotel $X$ ini juga memberikan pilihan yang bagus untuk keluarga yang sedang berlibur di Yogyakarta.
Berdasarkan hasil wawancara awal dengan manajer HRD Hotel $X$ diketahui bahwa terdapat beberapa masalah yang harus diselesaikan. Permasalahan pertama terdapat pada kegiatan Morning Breafing, manajer HRD mengatakan setiap paginya seluruh karyawan Hotel $\mathrm{X}$ melakukan pertemuan secara rutin. Pada saat pertemuan tersebut setiap karyawan memperoleh informasi-informasi baru mengenai kebijakan hotel dan juga dapat menyampaikan hambatan selama bekerja. Akan tetapi, pada kenyataannya, hampir 30 persen dari seluruh jumlah karyawan masih kurang memiliki kemauan untuk hadir dalam pertemuan tersebut. Menurut manajer HRD, beberapa karyawan menyampaikan merasa tidak penting untuk ikut dalam pertemuan tim tersebut.

Permasalahan selanjutnya diperoleh dari Dept. Head X, manajer HRD mendapat informasi bahwa terdapat beberapa Dept. Head $X$ yang tidak melakukan pekerjaannya sesuai dengan tugas dan tanggungjawab. Di Hotel $X$, seorang Dept. Head memiliki bawahan yang jabatannya adalah Second Line atau bisa disebut sebagai wakil Dept. Head. Pihak manajer HRD menyampaikan bahwa sering sekali Dept. Head $X$ tidak memberikan arahan mengenai pekerjaan atau tugas kepada bawahan dan tidak menyelesaikan pekerjaan secara bersama-sama dalam kelompok. Sebagai atasan seharus- 
nya seorang Dept. Head mampu menjadi panutan atau contoh kepada seluruh karyawan, sehingga proses pekerjaan menjadi lancar dan efektif.

Menurut Gordon (1990), rendahnya kohesivitas pada kelompok disebabkan beberapa faktor, yaitu rendahnya tingkat intensitas berkomunikasi anggota kelompok. Sebuah kelompok yang anggotanya jarang berkomunikasi satu sama lain tidak akan memperlihatkan kohesivitas sebaik kelompok-kelompok yang mempunyai tingkat komunikasi yang tinggi antar anggota. Dalam bekomunikasi pihak-pihak yang tekait saling berinteraksi menggunakan kemampuan berkomunikasi masing-masing untuk mencapai kesepakatan bersama. Dengan demikian, dapat dikatakan bahwa dalam proses terciptanya kohesivitas kelompok terdapat unsur komunikasi interpersonal yang dibangun antar kedua belah pihak.

Devito (1995) menjelaskan bahwa komunikasi interpersonal yang efektif mengandung unsur keterbukaan, yaitu kemampuan komunikator harus terbuka kepada orang yang diajaknya berinteraksi, harus ada kesediaan membuka diri, mengungkapkan informasi yang biasanya disembunyikan. Dari hasil wawancara, peneliti memperoleh informasi bahwa karyawan yang sering berhalangan hadir dalam kegiatan rutin tidak mampu menjelaskan alasan yang tepat kepada atasan.
Berkomunikasi interpersonal yang efektif merupakan salah satu strategi yang dapat meningkatakan kohektivitas kelompok dalam tim. Kemampuan berkomunikasi interpersonal yang efektif merupakan orientasi terhadap hubungan individu dan kelompok di mana hubungan tersebut dipandang sebagai sesuatu yang lebih permanen dan terpusat. Orientasi komunikasi interpersonal efektif tercermin dari lima dimensi yaitu keterbukaan, sikap positif, kesetaraan, sikap suportif dan empati terhadap kelompok. Pelatihan komunikasi interpersonal yang efektif juga diharapkan dapat mengembangkan kemampuan yang dimiliki karyawan agar dapat bekerja sesuai norma yang berlaku. Dengan terciptanya komunikasi yang efektif antar anggota kelompok diharapkan dapat meningkatkan kokampakan kelompok dalam tim, sehingga tujuan kelompok tercapai sesuai yang diharapkan dan profit perusahaan pun juga dapat meningkat.

Hipotesis yang diajukan dalam penelitian ini adalah pelatihan komunikasi interpersonal dapat meningkatkan kohesivitas kelompok karyawan. Kohesivitas kelompok akan meningkat setelah diberi pelatihan komunikasi interpersonal. 
METODE PENELITIAN

Rancangan Penelitian
Desain penelitian yang digunakan dalam penelitian ini adalah kuasi eksperimen. Rancancangan tersebut dapat dilihat pada gambit berikut:

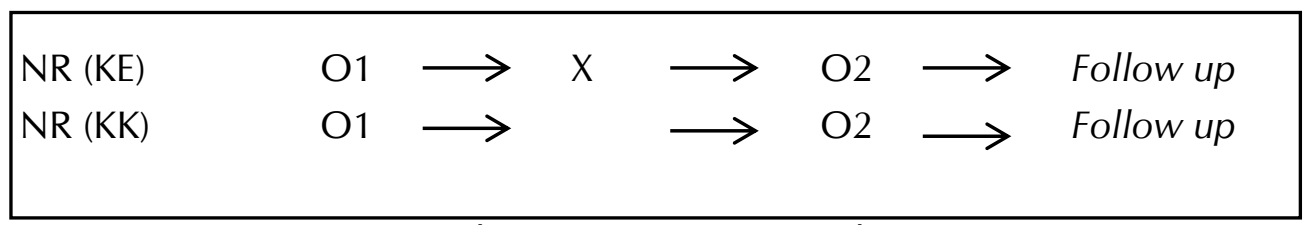

Gambar 1. Rancangan penelitian

Sumber : Shadish, Coock \& Campble (2002)

Keterangan :

KE : Kelompok eksperimen

KK : Kelompok kontrol

O1 : Pengukuran prates

O2 : Pengukuran pascates

X : Intervensi melalui Pelatihan komunikasi interpersonal

\section{Subjek Penelitian}

Penelitian ini melibatkan 22 orang karyawan hotel, yaitu 11 orang karyawan bertindak sebagai kelompok eksperimen dan 11 orang karyawan bertindak sebagai kelompok kontrol.

\section{Metode Pengumpulan Data}

Metode pengumpulan data yang digunakan dalam penelitian ini dengan adalah metode wawancara, observasi dan skala. Skala yang digunakan dalam penelitian ini adalah skala untuk mengukur kohesivitas kelompok dan tingkat komunikasi interpersonal. Skala kohesivitas dirancang berdasarkan dimensi kohesivitas kelompok yang dikemukakan Forsyth (2006) dalam empat dimensi, yaitu kekuatan sosial, kesatuan dalam kelompok, daya tarik dan kerjasama kelompok. Pada skala kohesivitas didapatkan skor koefisien validitas aitem sebesar 0,929.

\section{Intervensi}

Sebelum intervensi diberikan, beberapa persiapan dilakukan. Tahap awal persiapan adalah penyusunan alat ukur dan modul pelatihan komunikasi interpersonal divalidasi dengan professional judgement. Tahap berikut adalah uji coba modul pelatihan komunikasi interper- 
sonal dan angket kohesivitas kelompok. Persiapan terakhir adalah penentuan dan pembekalan fasilitator pelatihan.

Peserta pelatihan dipilih berdasarkan skor kohesivitas kelompok, yaitu skor yang sedang dan rendah. Tes diberikan satu minggu sebelum pelatihan komunikasi interpersonal dilakukan. Peserta dibagi ke dalam dua kelompok dan masing-masing peserta mengisi informed concent.

Intervensi yang diberikan adalah pelatihan komunikasi interpersonal. Materi dan desain pelatihan yang digunakan dalam peneltian ini disusun dengan menggunakan teori komunikasi interpersonal De Vito (1995). Pelatihan ini dilakukan dalam satu hari dengan enam sesi yaitu pengertian komunikasi interpersonal, keterbukaan, empati, sikap mendukung, sikap suportif, dan kesetaraan. Waktu yang dibutuhkan pada tiap sesi rata-rata adalah 50 menit. Pengukuran pascates dilakukan satu minggu setelah intervensi diberikan, sedangkan pengukuran tindak lanjut diberikan dua minggu setelah intervensi berlangsung.

\section{Metode Analisis Data}

Analisis data yang digunakan dalam penelitian ini adalah analisis non parametric karena jumlah sampelnya kecil (Ghozali \& Castellan, 2002). Pengujian perbedaan kohesivitas kelompok sebelum dengan sesudah pelatihan komunikasi interpersonal diberikan dengan teknik analisis U-Man Whitney. Dengan membandingkan hasil dari kelompok eksperimen yang dapat perlakukan dengan kelompok kontrol yang tidak mendapat perlakuan (Sugiyono, 2007), analisis ini dapat dilakukan dengan bantuan program SPSS 16 For Windows.

\section{HASIL PENELITIAN}

\section{Deskripsi Data}

Data yang diperoleh dari hasil pengukuran selanjutnya dianalisis lebih lanjut sehingga diperoleh deskripsi data penelitian berupa skor hipotetik dan skor empirik. Berikut adalah deskripsi data penelitian: 
Tabel 1. Deskripsi Data Penelitian

\begin{tabular}{llcccccccc}
\hline \multirow{2}{*}{ Data } & & \multicolumn{4}{c}{ Hipotetik } & \multicolumn{4}{c}{ Empirik } \\
\cline { 3 - 9 } & & Xmin & Xmax & Mean & SD & Xmin & Xmax & Mean & SD \\
\hline \multirow{2}{*}{ Prates } & KE & 78 & 136 & 107 & 21,4 & 78 & 136 & 102,73 & 16,584 \\
& KK & 81 & 121 & 101 & 20,2 & 81 & 121 & 105,64 & 11,952 \\
\hline \multirow{2}{*}{ Pascates } & KE & 87 & 140 & 113.5 & 22,7 & 87 & 140 & 113,18 & 16,154 \\
& KK & 75 & 111 & 93 & 18,6 & 75 & 111 & 89,9 & 11,484 \\
\hline Tindak & KE & 95 & 140 & 117.5 & 23,5 & 95 & 140 & 117,91 & 14,335 \\
Lanjut & KK & 88 & 121 & 104.5 & 20,9 & 88 & 121 & 102,09 & 9,23 \\
\hline
\end{tabular}

Keterangan:

$\begin{array}{ll}\mathrm{Xmin} & =\text { skor minimal } \\ \mathrm{KE} & =\text { Kelompok Eksperimen } \\ \mathrm{Xmax} & =\text { skor maksimal } \\ \mathrm{KK} & =\text { Kelompok Kontrol } \\ \mathrm{SD} & =\text { standar deviasi }\end{array}$

\section{Hasil Uji Asumsi}

Uji normalitas dilakukan dengan bantuan program SPSS 16 for Windows, menggunakan teknik one-sample Kolmogorof-Smirnov Test. Analisis dilakukan dengan melihat taraf signifikansi ( $p$ ) yang diperoleh. Sebuah sebaran data dikatakan

memiliki sebaran normal bila memiliki taraf signifikansi $p>0,05$. Berikut adalah hasil uji normalitas data prates, pascates, dan tindak lanjut pada kelompok eksperimen dan kelompok kontrol yang diperoleh:

Tabel 3. Hasil Uji Normalitas

\begin{tabular}{lcccc}
\hline \multicolumn{1}{c}{ Data } & & Skor KS-Z & $\mathbf{p}$ & Kategori \\
\hline Prates & KE & 0,422 & 0,994 & Normal \\
& KK & 0,683 & 0,739 & Normal \\
\hline Pascates & KE & 0,513 & 0,955 & Normal \\
& KK & 0,613 & 0,846 & Normal \\
\hline Tindak Lanjut & KE & 0,336 & 1,000 & Normal \\
& KK & 0,510 & 0,957 & Normal \\
\hline
\end{tabular}

Berdasarkan tabel uji normalitas dilihat bahwa data prates kelompok terhadap data penelitian di atas, dapat eksperimen memiliki sebaran data normal 
(nilai KS-Z sebesar 0,422 dengan nilai $p=0,994 \quad(p>0,05))$. Demikian halnya dengan data prates kelompok kontrol yang juga memiliki sebaran data normal (nilai KS-Z sebesar 0,683 dengan nilai $p=$ $0,739(p>0,05))$. Data pascates kelompok eksperimen juga memiliki sebaran data normal (nilai KS-z sebesar 0,513 dengan nilai $p=0,955(p>0,05))$. Selain itu, data pascates kelompok kontrol juga memiliki sebaran data normal (nilai KS-Z sebesar 0,613 dengan nilai $p=0,846$ ( $p$ $>0,05)$ ). Begitu juga data tindak lanjut kelompok eksperimen juga memiliki sebaran data normal (nilai KS-Z sebesar 0,336 dengan $p=1,000(p>0,05)$ ). Selain itu, data tidak lanjut kelompok kontrol juga memiliki sebaran normal (nilai KS-Z sebesar 0,510 dengan $p=0,957$ $(p>0,05))$. Dengan demikian, dapat disimpulkan bahwa seluruh data penelitian, yaitu data prates, pascates, dan tindak lanjut dari kelompok eksperimen maupun kelompok kontrol dalam penelitian ini memiliki distribusi sebaran data normal.

\section{Hasil Uji Hipotesis}

Analisis ini digunakan untuk mengetahui perbedaan pengaruh pelatihan komunikasi interpersonal terhadap peningkatan kohesivitas kelompok pada karyawan sebelum dan setelah diberikan perlakuan.

Hasil perhitungan uji beda pada kelompok eksperimen dan kelompok kontrol diperoleh $Z=-0,822$ dan skor $p=0,411$ sehingga $p>0,05$. Berdasarkan analisis uji Mann-whitney tersebut diketahui bahwa tidak ada perbedaan yang signifikan keahlian karyawan pada kelompok eksperimen dan kontrol sebelum diadakan pelatihan komunikasi interpersonal.

Hasil analisis pada skor pascates kelompok eksperimen dan kelompok kontrol, dapat diketahui bahwa nilai Z yang diperolah adalah sebesar $-3,124$ dengan taraf signifikansi 0,002 $(p<0,05)$. Hasil yang diperoleh menunjukkan terdapat perbedaaan skor yang signifikan antara kelompok eksperimen dan kelompok kontrol pada saat pascates.

Hasil analisis skor tindak lanjut kelompok eksperimen dan kelompok kontrol, dapat diketahui bahwa nilai Z yang diperolah adalah sebesar $-2,528$ dengan taraf signifikansi $0,011(p<0,05)$. Hasil yang diperoleh menunjukkan bahwa terdapat perbedaaan skor yang signifikan antara kelompok eksperimen dan kelompok kontrol pada saat tindak lanjut. 
Tabel 4. Hasil Mann-Whitney U Test Prates, Pascates, dan Tindak Lanjut Kelompok Eksperimen - Kontrol

\begin{tabular}{lccc}
\hline \multicolumn{1}{c}{ Kelompok } & Nilai Z & Sig. & Keterangan \\
\hline $\begin{array}{l}\text { Eksperimen } \\
\text { Kontrol Prates }\end{array}$ & $-0,822$ & 0,411 & Tidak Signifikan \\
\hline $\begin{array}{l}\text { Eksperimen } \\
\text { Kontrol Pascates }\end{array}$ & $-3,124$ & 0,002 & Signifikan \\
\hline $\begin{array}{l}\text { Eksperimen } \\
\text { Kontrol Tindak Lanjut }\end{array}$ & $-2,528$ & 0,011 & Signifikan \\
\hline
\end{tabular}

Berdasarkan hasil uji beda MannWhitney $U$ Test yang dilakukan antara kelompok eksperimen dan kelompok kontrol saat prates, pascates, dan tindak lanjut maka dapat disimpulkan bahwa hipotesis penelitian yang menyatakan terdapat pengaruh pelatihan komunikasi interpersonal untuk meningkatkan kohesivtias kelompok pada karyawan Hotel X Yogyakarta, diterima. Artinya Pelatihan komunikasi interpersonal yang diberikan terbukti mampu meningkatkan kohesivtias kelompok pada karyawan.

\section{PEMBAHASAN}

Penelitian ini bertujuan untuk mengetahui apakah komunikasi interpersonal dapat meningkatkan kohesivitas kelompok pada karyawan. Partisipan penelitian yang telah mengikuti perlakuan berupa pelatihan komunikasi interpersonal mengalami kenaikan kohesivitas kelompoknya. Berdasarkan hasil analisis data diketahui kelompok eksperimen mengalami kenaikan kohesivitas setelah mengikuti pelatihan komunikasi interpersonal. Terlihat dari skor nilai signifikansi yaitu $p=0,002$ yang artinya $p<0,05$ sehingga ada perbedaan yang signifikan antara kelompok ekperimen dan kelompok kontrol di mana ada peningkatan kohesivitas pada karyawan sebelum mengikuti dan setelah mengikuti pelatihan. Dengan demikian dapat disimpulkan bahwa hipotesis penelitian yang menyatakan terdapat pengaruh pelatihan komunikasi interpersonal terhadap kohesivitas kelompok pada karyawan Hotel $\mathrm{X}$ Yogyakarta diterima.

Salah satu pendekatan yang dilakukan peneliti guna meningkatkan kohesivitas kelompok pada karyawan adalah dengan memberikan pelatihan komunikasi interpersonal kepada karyawan hotel. Tujuan dari diadakannya pelatihan komunikasi interpersonal ini adalah melatih karyawan agar mampu memahami yang nantinya menerapkan keterbukaan, sikap mendukung, empati, sikap positif, dan kesetaraan. Diharapkan ketika karyawan berhadapan dengan rekan kerja 
dan pelanggan dapat menerapkan secara langsung komunikasi interpersonal yang efektif.

Bambacas dan Patrickson (2008) beranggapan bahwa keterampilan komunikasi interpersonal merupakan hal penting dikarenakan dapat menimbulkan kerjasama, mengurangi konflik yang pada gilirannya, meningkatkan komitmen, mengurangi kecenderungan untuk meninggalkan organisasi. Materi komunikasi interpersonal yang diberikan pada pelatihan membantu peserta untuk mengoptimalkan komunikasi interpersonalnya terutama dalam bersosialisasi dengan rekan kerja sehingga hubungan yang terjalin pada saat berinteraksi sesama rekan kerja menjadi yang lebih dekat dan personal. Ketika sesama karyawan dalam sebuah kelompok sudah menerapkan salah satu hal yang penting dalam berkomunikasi interpersonal, sebagai contoh sikap terbuka (keterbukaan) dalam menyampaikan masukan dan saran kepada rekan kerja maka dimungkinkan tidak ada kesalahpahaman dalam berkomunikasi selama berlang-sungnya interaksi.

Hasil penelitian ini sejalan dengan penelitian yang telah dilakukan Bachroni (2011) bahwa perubahan kohesivitas kelompok pada karyawan disebabkan oleh pembentukan tim yang baik dengan pemahamn setiap karyawan mengetahui tujuan secara bersama serta menyadari pentingnya tim dalam pencapaian kelompok. Begitu juga pada penelitian Sugadhi (2014) bahwa pembentukan tim dapat meningkatkan kohesivitas kelompok pada karaywan. Pemberian pemahaman tentang materi pembentukan tim merupakan salam satu proses meningkatnya kohesivitas dalam kelompok.

Pelatihan ini menggunakan lima konsep pembelajaran agar proses pembelajaran dapat efektif, yaitu motivasi, pengukuhan kembali, pengetahuan tentang hasil, praktek aktif dan pembelajaran melalui penghayatan (experiental learning), dan pemindahan dari pelatihan (Munandar, 2011). Desain pelatihan ini menggunakan aktivitas-aktivitas pembelajaran melalui pengalaman, yaitu suatu cara belajar melalui pengalaman sendiri kemudian memodifikasinya untuk meningkatkan keefektivitasannya dalam perlakuan positif. Tujuan dari pembelajaran melalui pengalaman adalah untuk mempengaruhi individu dalam tiga hal, yaitu merubah struktur kognitif peserta, memodifikasi sifat peserta, dan mengembangkan behavioral skill peserta.

Menurut hasil evaluasi pelatihan pengetahuan partisipan mengalami perubahan dari sebelum pelatihan dan setelah pelatihan komunikasi interpersonal. Hasil skor evaluasi pengetahuan didapatkan rata-rata sebelum pelatihan sebesar 73,636 dan skor evaluasi pengetahuan meningkat menjadi 94,545. 
Munandar (2011) mengatakan sering terjadi peserta yang mengikuti program pelatihan tidak berhasil menerapkan hasil dari pelatihan ke dalam situasi pekerjaan yang nyata. Untuk mengatasi hal ini diupayakan adanya unsur-unsur yang sama antara situasi nyata dengan situasi pelatihan. Dalam program pelatihan dapat juga diadakan diskusi secara bersama tentang apa saja yang peserta alami jika pengetahuan, keterampilan dan sikap peserta pelajari dalam pelatihan diterapkan dalam situasi kerja nyata. Diharap-kan apa yang peserta pelajari dapat ber-guna dalam pekerjaan nyata.

Hull (Munandar 2011) mengatakan peningkatan pembelajaran seseorang dalam pelatihan oleh beberapa faktor. Faktor tersebut salah satunya adalah adanya dorongan yang kuat atau motivasi dari para peserta dalam mengikuti pelatihan, hal ini terlihat pada sikap, antusias, dan keaktifan peserta selama pelatihan. Proses tanya jawab, diskusi, bermain peran membuat peserta percaya diri dalam mengungkapkan pendapatnya.

Peserta dalam kelompok eksperimen telah dapat menerapkan beberapa materi pelatihan dalam kehidupan seharihari khususnya dalam tempat kerja. Hal ini didukung hasil wawancara singkat dengan beberapa peserta dua minggu setelah mengikuti pelatihan komunikasi interpersonal. Partisipan bernama Fulan menunjukkan bahwa perubahan yang dirasakan setelah mengikuti pelatihan adalah menjadi lebih terbuka dalam berkomunikasi dan tanpa harus ada yang disembunyikan sesama rekan kerja. Fulan juga menyampaikan terdapat beberapa rekan kerja lebih bisa menerima kekurangan dan kelebihan rekan kerjanya, yang awalnya masih tidak bisa saling percaya dalam pekerjaan. Hal ini sangat berguna dalam tercapainya kesuksesan pekerjaan. Fulan juga mengatakan bahwa dirinya lebih mampu bersosialisasi dengan baik dengan lingkungan kerja. Selain itu, hasil wawancara dengan partisipan Anon memperoleh beberapa data mengenai perubahan setelah pelatihan. Partisipan Anon menyampaikan bahwa dirinya lebih komunikatif sesama rekan kerja dan mampu menyelesaikan secara langsung permasalahan ketika ada masalah yang dirinya hadapi dengan rekan kerja.

Dapat disimpulkan bahwa pelatihan komunikasi interpersonal dapat dipahami secara pengetahuan dan dapat mengubah perilaku partisipan. Hal tersebut terjadi akibat pengaruh faktor pengalaman yang telah diberikan sebelumnya pada saat pelatihan. Breckler dan Wiggins (Azwar, 2008) menyebutkan bahwa sikap yang diperoleh dari pengalaman akan menimbulkan pengaruh langsung terhadap perilaku berikutnya. Pengaruh langsung tersebut lebih berupa predisposisi perilaku yang akan di- 
realisasikan hanya apabila kondisi dan situasi memungkinkan (Azwar, 2008).

Hasil dari penelitian menunjukkan bahwa pelatihan komunikasi interpersonal dapat meningkatkan kohesivitas kelompok pada karyawan Hotel X Yogyakarta. Namun, penelitian ini masih memiliki beberapa keterbatasan yang mengancam validitas penelitian baik validitas internal maupun eksternal. Pengambilan data menggunakan skala dapat mengancam faktor instrumentasi. Proses pengisian dengan skala memungkinkan partisipan untuk mengisinya dengan respon-respon kecenderungan baik, social desirability, respon subjektif, dan dapat dipengaruhi suasana hati (mood), kondisi, dan situasi sekitar (Azwar, 2005). Oleh karena itu, pengam-bilan data menggunakan skala yang tidak dibarengi dengan wawancara dan observasi lebih lanjut dapat mengurangi validitas hasil penelitian. Waktu yang terlalu panjang dan lama yaitu 8 jam juga menjadi ancaman untuk faktor maturasi. Materi yang banyak dapat mempengaruhi kejenuhan, kelelahan, kebosanan, konsentrasi mendengarkan materi sehingga pemahaman peserta kurang baik terkait dengan isi materi yang diberikan.

\section{SIMPULAN DAN SARAN}

\section{Simpulan}

Berdasarkan hasil analisis data dan pembahasan tersebut di atas, dapat di- simpulkan bahwa pelatihan komunikasi interpersonal dapat meningkatkan kohesivitas kelompok pada karyawan Hotel $\mathrm{X}$ Yogyakarta. Pada evaluasi pelatihan bahwa pengetahuan partisipan pada kelompok eksperimen mengalami perubahan akibat dari pelatihan komunikasi interpersonal yang dilaksanakan, partisipan kelompok eksperimen mengalami peningkatan pengetahuan terkait komunikasi interpersonal.

\section{Saran}

Penelitian ini tentu juga memiliki beberapa keterbatasan, untuk itu ada beberapa saran yang perlu dikemukakan disini khususnya bagi peneliti yang akan melakukan penelitian serupa berikutnya.

Saran kepada penelitian selanjutnya adalah terkait tempat pelatihan. Hal ini dikarenakan tempat pelatihan dan kerja menjadi satu. Sehingga banyak peserta yang tidak fokus dalam menerima materi karena sering keluar masuk ruangan untuk melakukan pekerjaan di kantor. Peneliti menyarankan pemilihan tempat pelatihan lebih baik diluar tempat kerja peserta, sehingga peserta lebih fokus dalam mengikuti pelatihan.

\section{DAFTAR PUSTAKA}

Afdjani, H. (2013). Ilmu Komunikasi Proses \& Strategi. Tangerang: Indigo Media 
Azwar, S. (2005). Reliabilitas dan Validitas. Yogyakarta: Pustaka Belajar

Azwar, S. (2008). Penyusunan Skala Psikologi (Cet VII). Yogyakarta: Pustaka Belajar Offset

Bachroni, M (2011). Pelatihan Pembentukan Tim untuk Meningkatkan Kohesivitas Tim pada Kopertis $V$ Yogyakarta, Jurnal Psikologi Volume 38, No 1. Yogyakarta : Fakultas Psikologi Universitas Gajah Mada

Bamcass, $M$, \& Patrickson, $M$, Interpersonal Communication Skill That Enhance Organization Commitment: Journal of Communication Management, 12 (1), 51, 2008

Carron, A.V. dkk. (2000) Team cohession and Team Success In Sport. Journal of Sport Science, 20, 119-127

Cumming, T.G \& Worley, C.G. (2005). Organization Development and Change : Eight Edition. New York : Thomson South Westren

Davis, K \& Newstrom, J. W. (2001). Perilaku dalam Organisasi Jilid 1. Jakarta : Erlangga

De Vito, J. A. (1995). The Interpersonal Communication book $\left(7^{\text {th }} \mathrm{Ed}\right)$. New York : Harper Collins College Publisher
Dessler, G. (2004). Manajemen Sumber Daya Manusia. Terjemahan. Jakarta: Indeks

Dyaram, L., \& Kamalanabhan., T.J (2005). Unearthed: The Slide of Group Cohesiveness. New Delhi: Journal Sosial Sciene, 10 (3): 185-190

Douglas, T.(1993). A Theory of Groupwork Practice. London: MacMilan

Forsyth, D, R. (2006). Group Dynamics Fourth. Thompson Wardsworth Learning

Hardjana, A, M. (2001). Training SDM yang Efektif. Yogyakarta: Kanisius

Ivancevich, J, M., Konopaske, R., \& Matteson, M, T. (2006). Perilaku dan Manajemen Organisasi. Jakarta: Erlangga

Latipun. (2009). Psikologi Ekperimen Edisi Pertama. Malang: UMM Press

Lestasi, N, A. (2014). Pengaruh pelatihan komunikasi interpersonal terhadap kemampuan negoisasi karyawan di hotel x. Tesis, tidak diterbitkan. Yogyakarta: Magiter Profesi Psikologi UII

Levi, D. (2001). Dynamic Group for Teams. London: Sage Publications

Mangkuprawira, S, \& Hubeis. A, V. (2007). Manajemen Mutu Sumber 
Daya Manusia. Bogor: Galia Indonesia

Martika, L, D (2013). Studi Deskripsi Kohesivitas Kelompok Karaywan di Yayasan Nurul Hayat Surabaya. Jurnal IImiah Universitas Surabaya. Surabaya: Fakultas Bisnis dan Ekonomika

Masyhuri, (2005). Hubungan antara komunikasi interpersonal dan budaya organisasi dengan kepuasan kerja pegawai dinas PU Kimpraswil Kabupaten Kampar, Riau. Tesis, tidak diterbitkan. Yogyakarta: Program Studi Psikologi Industri UGM.

Munandar. A. S. (2011). Psikologi Industri dan Organisasi. Jakarta: UI-Press

Paris, C. R., Salas, E. \& Bowers, J. A. C. (2000). Teamwork in Multi-person System: A Review and Analysis. Journal of Ergonomic, 43. 1052-107

Prihadi, S, F. (2004). Assesment Center: Identifikasi Pengukuran dan Pengembangan Kompetensi. Jakarta : PT. Gamedia Pustaka Utama

Rakhmat, J. (2013). Psikologi Komunikasi. Bandung: PT Remaja Rosdakarya

Robbins, S, P. (2008). Perilaku Organisasi. New Jersey: Prentice Hal I
Sadish, W.R., Cook, T.D, \& Campbell, D.T., (2009). Experimental And Quasi Experimental Design For Generalized Causal Inference. Boston: Houghton Mifflin Company.

Smither, R. D., Jouston, J, M \& Mclntire, S, A. (1996). Organization Development Strategies for Changing Enviroments. Florida: HarperCollins College Publishers

Soetopo. H, (2010,). Perilaku Organisasi, Malang: PT Remaja Rosdakarya

Suciati, (2015). Komunikasi Interpersonal Sebuah Tinjauan Psikologis dan Perspektif Islam, Buku Litera: Yogyakarta

Sugandhi, R. (2014). Pengaruh pelatihan pembentukan tim dalam meningkatkan kohesivitas kelompok karyawan hotel $\mathrm{x}$. Tesis, tidak diterbitkan. Yogyakarta: Magister Profesi Psikologi UII

Sugiyono. (2003). Statistika untuk Penelitian. Alfabeta, Bandung.

Sumantri, S. (2000), Pelatihan dan Pengembangan Sumber Daya Manusia, Bandung: Fakultas Psikologi Unpad.

Suranto, A. W. (2011). Komunikasi Interpersonal. Yogyakarta: Graha Ilmu 
Suryana, A. (2004). Kiat dan Teknik Evaluasi Pelatihan. Jakarta: Progres

Thoha, M. (1983). Perilaku Organisasi Konsep Dasar dan Aplikasinya. Jakarta: PT. Raja Grafindo Persada

Trihapsari \& Nashori (2011). Kohesivitas Kelompok dan Komitmen Organisasi pada Financial Advisor Asuran- si X Yogyakrta. Jurnal Psikologi. Yogyakarta: Fakultas Psikologi dan Ilmu Sosial Budaya UII.

Yulianto. F, (2010). Pelatihan konsep diri untuk meningkatkan kemampuan komunikasi interpersonal pada karaywan di Biro. Tesis, tidak diterbitkan. Yogyakarta: Magister Profesi Psikologi UII. 